\title{
UMA LEITURA EXTRAVAGANTE DA SEMÂNTICA FREGEANA
}

\author{
Claudio F. Costa \\ Universidade Federal do Rio Grande do Norte
}

\begin{abstract}
This paper contains a reconstruction of the basic ideas of the fregean semantics in which senses are paraphrased as cognitive rules and existence and truth as the aplicabilitiy of these rules. Some of the most implausible fregean suggestions are rejected and their replacement by more intuitive candidates is considered, along with the speculative consequences of these choices.
\end{abstract}

Keywords: Fregue, sense and reference, semantics.

Resumo: Esse artigo contém uma leitura da semântica fregeana na qual sentidos são parafraseados como regras cognitivas e a existência e a verdade em termos da aplicabilidade dessas regras. Nesse contexto idéias objetáveis da semântica fregeana são substituidas por outras mais intuitivas e plausíveis, sendo as consequências disso especulativamente consideradas.

Palavras-chave: Frege, sentido e referência, semântica.

A importância da semântica fregeana para a filosofia da linguagem consiste em sua conjunção única de simplicidade teórica com amplitude explicativa e relevância filosófica. Quero aqui interpretar as suas idéias básicas tentando demonstrar que os seus conceitos semânticos podem ser analisados em termos de regras cognitivas. Essa idéia já foi sustentada por Michael Dummett e outros, mas acho que mereceria ser mais sistematicamente explorada. Tudo o que apresentarei, porém, são sugestões conjecturais que clamam por elaboração. Meu objetivo aqui não é apresentar resultados, mas testar idéias, o que não deixa, aliás, de ser um procedimento filosófico. 
Como é bem sabido, Frege explica a referência (Bedeutung) recorrendo a um elo semântico intermediário, por ele chamado de sentido (Sinn). O esquema (1) mostra como Frege considera esses dois níveis, tendo em vista o caso fundamental da frase predicativa singular:

(1)

termo singular termo geral frase

Sentido modo de apresentação ? pensamento

Referência objeto conceito > objeto valor-verdade

Embora a semântica fregeana seja um desenvolvimento de incomparável importância para a filosofia da linguagem, ela não é isenta de bem conhecidas excentricidades. A própria análise de seus principais elementos semânticos em termos de regras irá sugerir algumas maneiras de expurgá-la de suas maiores estranhezas.

\section{Referência do termo singular}

Comecemos com os termos singulares. A referência de um termo singular é, para Frege, o próprio objeto por ele referido, tomado no sentido mais amplo. A referência do nome 'Lua', por exemplo, é a própria Lua com as suas crateras... Para designar a referência ele usa a palavra alemã 'Bedeutung', cuja tradução literal para o português é 'significado' e para o inglês é 'meaning'. Os lúcidos tradutores ingleses preferiram palavras como 'reference', 'denotation' e 'nominatum', que exprimem o que Frege realmente tinha em mente. Outros termos usados foram ainda 'semantic value', 'semantic role' e 'truth-value potential', que salientam a contribuição das referências dos componentes da frase para o valor-verdade da frase como um todo. A tradução mais fiel ao texto original é a literal, ou seja, 'meaning' em inglês e 'significado' em português; mas por razões de sistematicidade e clareza, manterei aqui a palavra 'referência'. 1

Há uma discussão entre intérpretes sobre a razão pela qual Frege teria escolhido a palavra 'Bedeutung'. Uma delas seria a de que um dos

1 Sobre a espinhosa questão de como traduzir 'Bedeutung', ver M. Beaney (ed.): The Frege Reader (Blackwell: Oxford 1997), p. 36 ss. 
significados de 'Bedeutung' (como também de 'significado' e 'meaning') é relevância ou importância, posto que a referência é aquilo que mais importa. $^{2}$ A razão mais forte, contudo, ao menos no que concerne à referência de termos singulares, é que ao introduzir o termo 'Bedeutung' Frege estaria substantivando o verbo 'bedeuten', usado para expressar, não mais o apontar (deuten), o designar (bezeichnen), mas já aquilo que é apontado (die Bedeutung), aquilo que é designado (das Bezeichnete), ou seja, a própria referência. ${ }^{3}$ Em alemão isso ficaria como:

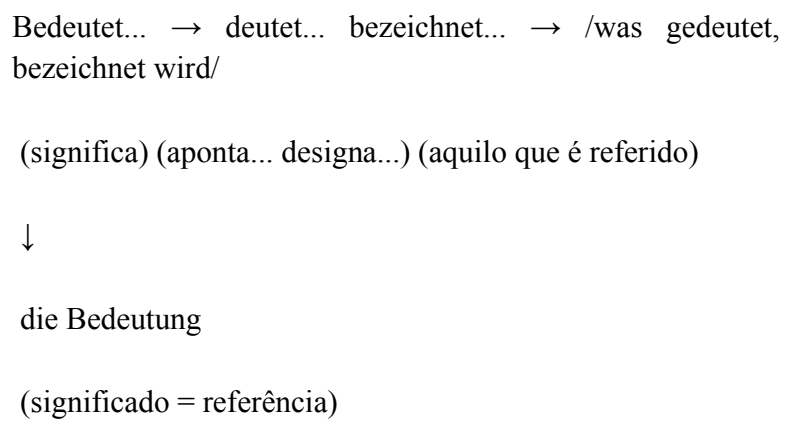

Essa teria sido a pequena torção semântica com a qual Frege transformou palavra 'Bedeutung' em um termo técnico, uma torção que trai um resquício de referencialismo semântico. ${ }^{4}$

\section{Sentido do termo singular}

Passemos agora ao sentido do termo singular. Para introduzi-lo, compare as duas seguintes frases:

\footnotetext{
2 Ernst Tugendhat: "Die Bedeutung des Ausdrucks 'Bedeutung' bei Frege", Philosophische Aufsätze (Frankfurt: Suhrkamp 1992). p. 231.

${ }_{3}$ Procurando na literatura vejo que esse ponto já foi notado por W. Kneale e M. Kneale em The Development of Logic, (Oxford: Clarendon Press 1962), p. 495.

4 Ver a introdução da distinção em "Funktion und Begriff" (Vandenhoeck \& Ruprecht: Goethingen 1980), p. 14 (paginação original).
} 
1.A estrela da manhã possui uma densa atmosfera de $\mathrm{CO} 2$.

2. A estrela da tarde tem possui densa atmosfera de $\mathrm{CO} 2$.

As frases (1) e (2) referem-se a mesma coisa, que é o planeta Vênus. Mas apesar disso, uma pessoa pode saber a verdade de (1) sem saber a verdade de (2). A explicação disso é que embora os termos singulares 'estrela da manhã' e 'estrela da tarde' se refiram ao mesmo planeta Vênus, eles veiculam conteúdos informativos diferentes, eles têm sentidos (Sinne) diferentes. O sentido é definido por Frege como sendo o modo de se dar do objeto (die Art des Gegebenseins des Gegenstandes), o que bem se traduz como o seu modo de apresentação. Os sentidos dos termos singulares 'estrela da manhã' e 'estrela da tarde' são diferentes porque o primeiro termo singular apresenta Vênus como o corpo celeste mais brilhante geralmente visto próximo ao horizonte pouco antes do sol nascer, enquanto o segundo apresenta o mesmo planeta Vênus como o corpo celeste mais brilhante geralmente visto próximo ao horizonte pouco depois do sol se por.

Segundo Frege, palavras expressam o sentido (drücken den Sinn aus) enquanto o sentido determina (bestimmt) a referência. O sentido é condição para a referência: ele mostra o caminho para a referência, mesmo nos casos em que ela não existe, daí ele também ter sido interpretado como sendo o modo de apresentação pretendido e não necessariamente dado. ${ }^{5}$ Por isso uma expressão pode ter sentido sem ter referência, mas não pode ter referência sem ter sentido.

A noção de sentido em Frege é abrangente, constituindo o que ele chama de valor epistêmico (Erkenntniswert). O sentido fregeano possui interesse epistemológico por envolver o conteúdo informativo da expressão lingüística; ele é, no dizer de Michael Dummett, aquilo que entendemos quando entendemos a expressão. ${ }^{6}$ A importância filosófica da semântica fregeana resulta dessa importância epistemológica do seu conceito de sentido.

Frege concebe os sentidos como entidades abstratas, que ele só analisa em termos de outros sentidos que lhe sejam constituintes. Ou seja: ele não analisa os sentidos através de outros conceitos. Essa análise, porém,

${ }^{5}$ Max Textor: Frege on Sense and Reference (Routledge: New York 2011), p. 134.

${ }^{6}$ M. Dummett: Frege: Philosophy of Language (Duckworth: London 1981), p. 92. 
é algo que naturalmente se impõe. Pois parece muito plausível entendermos os sentidos fregeanos como sendo regras criteriais semântico-cognitivas. Aqui reside a conexão fundamental a ser feita entre as reflexões semânticas de Frege e do último Wittgenstein. ${ }^{7}$ A plausibilidade dessa identificação fica particularmente clara quando tomamos expressões numéricas como exemplos. Considere as expressões " $1+1$ ", “6/3", " 2 . $(7+3-9)$ ". Todas elas têm a mesma referência, o número 2 , mas sentidos fregeanos diferentes. Ao mesmo tempo elas constituem métodos, procedimentos, regras semântico-cognitivas diversas, através das quais identificamos o mesmo número $2 .^{8}$

Outra razão para tratarmos sentidos como regras semânticocognitivas é o contraste com o que Frege chamou de colorações (Färbungen). Colorações são o mesmo que sentidos expressivos, ou seja, estados afetivos que regularmente associamos a certas expressões. Assim, as palavras 'amor' e 'cão do inferno', na frase “O amor é um cão do inferno" (Bukowski), se associam contrastivamente a emoções específicas. Como Frege percebeu, a fixação de colorações emocionais similares a uma mesma palavra por diferentes pessoas depende da relativa semelhança entre as naturezas humanas dos falantes, não se fundamentando, pois, em convenções, diversamente dos sentidos. Por isso alguns gostam de certas poesias, outros não. E por isso é tão difícil traduzir poesia, que em muito depende das colorações adquiridas por uma expressão em certa língua. Podemos assim supor que a razão da objetividade (intersubjetividade) e conseqüente comunicabilidade dos sentidos - em contraste com a relativa falta de objetividade das colorações - está em que os sentidos são regras cognitivas convencionadas de modo geralmente pré-reflexivo, quando não são, supostamente, o que as combinações dessas regras constituem.

À luz dessas suposições, o sentido do termo singular deve ser considerado o mesmo que uma regra ou método ou procedimento convencionalmente fundado, cuja função é a de servir de caminho para a identificação do objeto como sendo o planeta Vênus. Essa regra se deixa ao

\footnotetext{
${ }^{7}$ Esse entendimento se deve principalmente a Michael Dummett. Mas orientações semelhantes podem ser encontradas em autores como P.F. Strawson e Ernst Tugendhat, entre outros.

${ }^{8}$ Ver comentários de Edmund Runggaldier sobre a interpretação de Dummett em seu livro Zeichen und Bezeichnetes: sprachphilosophische Untersuchungen zum Problem der Referenz (Walter der Gruyter: Berlin 1985), p. 91 ss.
} 
menos parcialmente exprimir por descrições. Assim, a regra associada ao termo singular 'a estrela da manhã' deixa-se explicitar pela descrição definida 'o corpo celeste mais luminoso geralmente visto próximo do horizonte pouco antes do sol nascer...' E um nome próprio como 'Aristóteles', como Frege notou, tem como sentidos distintos modos de apresentação do objeto, expressos por descrições como (i) 'discípulo de Platão e tutor de Alexandre o Grande' ou (ii) 'pessoa nascida em Estagira'. Segundo a interpretação proposta, (i) e (ii) exprimem diferentes sentidos, diferentes regras para a identificação de Aristóteles. Além disso, podemos suspeitar que (i) e (ii) façam parte de alguma regra mais geral estabelecedora de um vínculo unificador dessas duas regras na identificação de um mesmo objeto. Mesmo sob essa paráfrase o sentido determina a referência: para que se identifique a referência é preciso que regras semânticas identificadoras do objeto se demonstrem aplicáveis, ou seja, que as configurações criteriais por ela geradas sejam adequadamente satisfeitas.

\section{Referência do termo geral}

Frege tem algo a dizer sobre a referência do termo geral em função predicativa, a qual ele chama de conceito (Begriff). Isso é estranho porque parece natural pensarmos o conceito como sendo o próprio sentido da expressão conceitual, o seu modo de apresentação da referência, a qual deveria ser mas propriamente o que chamamos de propriedade. Além disso, para Frege o conceito é uma função. O conceito matemático de função pode ser definido como sendo uma regra que tem como input argumentos e como output valores (por exemplo: ' $3+x=\ldots$ '. é uma função que recebe como valor o número 6 quando o argumento que substitui $x$ é o número 2). Para ele um conceito é uma função cujo argumento é o objeto que "sob ele cai” (fällt unter) e cujo valor é um valor-verdade, que pode ser o verdadeiro ou o falso. Assim, o conceito designado pela expressão conceitual '...é branco' tem o valor verdadeiro quando sob ele cai o objeto Lua e tem o valor falso quando sob ele cai o objeto Sol.

9 Gottlob Frege: "Über Sinn und Bedeutung", Zeitschrift für Philosophie und philosophische Kritik, NF 100,1892 , p. 28 (paginação original). 
Frege nunca explicou satisfatoriamente o que são conceitos entendidos nesse sentido referencial. Para ele conceitos não podem ser nem objetos nem coleções de objetos nem extensões. ${ }^{10}$ A razão disso é que o objeto, a coleção de objetos, a extensão, é uma entidade independente (unabhängig), não precisando de nada para completá-la. O conceito, por contraste, sendo uma função, se caracteriza por ser aberto, ou seja, uma entidade incompleta (unvollständig) ou insaturada (ungesätig), precisando ser sempre preenchida por argumentos, que no caso são os objetos que sob ele podem cair. Esses objetos, por contraste, são completos, saturados ou independentes (unabhängig).

Por exemplo: o predicado '...é um cavalo' é uma expressão insaturada, designando um conceito também insaturado, que se deixa completar pelo objeto que sob ele cai, o qual é referido por um termo singular, por exemplo, 'Bucéfalo'. Predicado incompleto e termo singular completo se combinam para formar a frase completa "Bucéfalo é um cavalo", que por ser completa deve outra vez ser nome de objeto. Que a frase completa se refere a um objeto parece ser confirmado pela possibilidade que temos de nominalizar frases transformando-as em descrições definidas (aquelas que se iniciam com o artigo definido) como, por exemplo, 'o cavalo de nome Bucéfalo', que pode comparecer na frase "O cavalo de nome Bucéfalo pertenceu a Alexandre".

\section{O status ontológico da referência das expressões predicativas}

A discussão sobre a natureza insaturada da referência das expressões predicativas nos leva a questão da natureza ontológica do que Frege entende por conceito. A sua identificação da referência da expressão predicativa com o conceito é dificilmente defensável. Frege (diversamente de Gareth Evans) tem o bom senso de admitir que conceitos vazios existem. O termo predicativo '...é um unicórnio' refere-se para ele a um conceito, mesmo que sob ele não caia nenhum objeto. Contudo, parece intuitivamente claro que '...é um unicórnio' não possui referência alguma, embora obviamente expresse um conceito. Minha conclusão é a de que a identificação fregeana

10 G. Frege: "Ausführungen über Sinn und Bedeutung" in H. Hermes, F. Kambartel, F. Kaulbach (eds.): Nachgelassene Schriften (Felix Meiner: Hamburg1969). 
da referência da expressão predicativa com o conceito é incoerente, resultando de uma contaminação do domínio do sentido - no qual falamos de conceitos como modos de apresentação - pelo domínio da referência. A melhor opção parece ser a de admitir que o conceito seja mesmo o sentido do termo geral em sua função predicativa, o seu modo de apresentação, e que a sua referência seja alguma outra coisa que, com efeito, "cai sob" esse conceito, mesmo que ela não seja algo completo como um objeto ou extensão. Mas que coisa é essa?

Quero aqui propor a única resposta que me parece viável. Quero revisar Frege, interpretando a referência da expressão predicativa em termos do que hoje chamamos de tropos, que nada mais são do que propriedades espaço-temporalmente singularizadas, como o branco que vemos quando olhamos para a Lua e que, de certo modo, está lá (a reflexão do conjunto dos comprimentos de onda do espectro). Em sua forma mais conseqüente, a moderna ontologia dos tropos surgida em 1953 sustenta que toda a realidade deve ser constituída de tropos, os quais são as suas pedrinhas de construção. ${ }^{11}$ Nesse sentido, essa superfície rugosa e lisa que toco, o branco que vejo agora, aquele som agudo que acabei de ouvir, e mesmo (talvez) essa forma quadrática do apagador de giz que percebo diante de mim, são tropos. Universais poderiam ser definidos como tropos iguais a um tropomodelo $\mathrm{T}^{*}$ (o qual pode variar com o sujeito cognitivo e mesmo para o mesmo sujeito em diferentes ocasiões). ${ }^{12} \mathrm{E}$ objetos materiais que poderiam ser analisados como sistemas co-localizados e co-temporais de tropos, contendo núcleos de tropos eventualmente essenciais, circundados de tropos contingentes. ${ }^{13}$

Embora a ontologia dos tropos seja uma aquisição muito jovem e traga consigo muitos problemas irresolvidos, ela não produz mais dificuldades do que as tradicionais doutrinas universais do realismo e do nominalismo. Em compensação, ela promete uma solução extremamente

\footnotetext{
${ }^{11}$ A teoria dos tropos foi introduzida pelo filósofo australiano D.C. Williams em seu artigo "The Elements of Being", Review of Metaphysics, vol. 7, 1953, tendo desde então suscitado crescente interesse.

12 Assim é que tento caracterizar os universais de modo a contornar o usual mas problemático recurso a classes de tropos iguais entre si. C.F. Costa: "A teoria dos tropos e a insustentável levesa do ser" (artigo a ser publicado).

13 Embora carecendo de desenvolvimento adequado, uma sugestão semelhante foi feita por Paul Simons em "Particulars in Particular Clothing: Three Trope Theories of Substance", Philosophy and Phenomenological Research 54, 1994, pp. 553-575.
} 
econômica para os problemas ontológicos, libertando-nos, finalmente, de entidades questionáveis como universais platônico-aristotélicos e substâncias incognoscíveis, as quais ocuparam as cabeças filosóficas por mais de dois milênios sem um progresso que as tornasse mais plausíveis. Como não é aqui o lugar para fazer a defesa de uma ontologia dos tropos, posso propor ao leitor a admissão bem menos polêmica de que nossos termos empíricos se referem usando como critérios propriedades singularizadas, ou seja, tropos, como o desse vermelho e o daquele som agudo. Essa suposição de bom senso já bastará.

Segundo a releitura que proponho, a expressão predicativa '...é branco' na frase "A Lua é branca" tem como referência não um conceito, mas uma propriedade singularizada: o conjuntos das arranjos de tropos iguais que constituem a brancura da Lua (ou seja, das associações dadas a cada observador etc). Também aqui a propriedade (esse conjunto de arranjos de tropos iguais entre si) pode ser interpretada como uma função. Ela é uma função cujo argumento no caso é o objeto Lua, e cujo valor poderia ser simplesmente o fato de a Lua ser branca. Nesse caso, a função referida pela expressão predicativa '...é branca' seria satisfeita pelo objeto referido pelo nome 'Lua', dando como valor o estado de coisas (o fato) referido pela frase "A Lua é branca". (Essa seria uma opção ao artificioso recurso fregeano ao valor-verdade como o valor da função conceitual.)

\section{Insaturação como dependência ontológica}

Um problema com a idéia de incompletude ou insaturação é que ela não parece suficiente para distinguir a função predicativa. Entre o objeto e a propriedade designada pelo predicado vige uma bem conhecida assimetria: o objeto é normalmente referido pelo sujeito e a propriedade é normalmente referida pelo predicado (ex: "Sócrates é sábio"); mas enquanto a propriedade pode passar a ser referida pelo sujeito ("Sabedoria é uma virtude"), o objeto não pode passar a ser referido pelo predicado ("Sábio é Sócrates" não faz sentido, a não ser que 'sábio é...' seja entendido como predicado). Contudo, a distinção saturado/insaturado nada parece fazer para explicar essa assimetria. Afinal, parece igualmente possível afirmar que os termos singulares e, por conseguinte, os seus referentes, são insaturados. Afinal, qual a diferença entre os preenchimentos de "(Bucéfalo, Silver, Pégaso...) ...é um cavalo" e "Bucéfalo é... (branco, indócil, veloz...)"? Tanto 
o termo geral quanto o termo singular podem ser vistos como exprimindo funções que podem ser completadas por uma infinidade de outros termos, o mesmo se aplicando aos seus supostos referentes.

Contudo, a noção de insaturação insinua algo mais do que isso. Em química um composto de carbono é dito insaturado quando contém ligações carbono-carbono removíveis pela adição de átomos de hidrogênio, o que torna o composto saturado. Haveria uma maneira de resgatar essa metáfora? Será que Frege não a explorou suficientemente?

Quero mostrar que o recurso a uma leitura da referência da expressão predicativa em termos de tropos-funções nos possibilita uma paráfrase esclarecedora da distinção fregeana entre saturação e insaturação. Essa paráfrase inspira-se em uma das definições aristotélicas de substância como sendo aquilo que existe na independência de outras coisas. ${ }^{14}$ Aplicada aos objetos como sistemas de tropos, a intuição passa a ser a de que o sistema de propriedades singularizadas reconhecível enquanto tal é algo complexo e geralmente mais estável do que as propriedades isoladas, existindo de maneira relativamente independente dos tropos a ele associados. Troos não existem sozinhos: um tropo de verde, por exemplo, nunca existe na independência de um tropo de forma, que para se localizar precisa estar espaço-temporalmente relacionado a outros tropos etc. Admitindo que tropos isolados têm a sua existência dependente de objetos (particulares), os quais constituem-se (talvez só em parte) de sistemas relativamente independentes e estáveis de tropos, podemos fazer o seguinte raciocínio: se os referentes de termos gerais (empíricos) forem tropos (propriedades espaço-temporalmente localizadas), parece que podemos parafrasear melhor a dicotomia insaturação/saturação ou incompletude/completude através da dicotomia dependência/independência, raramente usada por Frege. Afinal, o que distingue a referência de um termo geral, no caso da frase predicativa ou mesmo relacional singular, é que essa referência é um tropo (ou complexo de tropos) cuja existência depende de um todo que é o sistema de tropos constitutivo do objeto particular referido pelo termo singular. Assim, o predicado '...é rápido' na frase "Bucéfalo é rápido" e a relação '...pertence a...' na frase "Bucéfalo pertence a Alexandre" aplicam-se respectivamente às combinações de tropos próprias do ser rápido e do pertencer a Alexandre,

\footnotetext{
${ }^{14}$ Aristóteles: Categorias, sec. 5.
} 
as quais só podem mesmo existir e se tornar identificáveis na dependência da existência de sistemas de tropos mais complexos, estáveis, independentes, que são os sistemas constitutivos dos objetos Bucéfalo e Alexandre. Já os sistemas de tropos constitutivos dos referentes dos nomes próprios 'Bucéfalo' e 'Alexandre' são objetos que ceertamente existem na independência da existência das combinações de tropos constitutivas do "ser rápido" ou do "pertencer a alguém". Sugiro, pois, que as propriedades referidas pelos predicados possuem uma inevitável relação de dependência para com objetos particulares e que isso se deixa melhor explicar quando nós a entendemos como sendo propriedades singularizadas ou tropos.

Note-se que a relação de dependência/independência não se preservaria se conceitos fossem extensões de expressões conceituais (classes de objetos aos quais certas propriedades singularizadas se aplicam). A relação de dependência/independência só se preserva quando entendemos a referência do predicado em termos de propriedades singularizadas. Tal relação tem sua origem ao nível ontológico da referência, mas ela se reflete ao nível da linguagem, na distinção lógica entre sujeito e predicado, e ainda, como veremos, ao nível epistemológico, pelo fato de que o sentido, o modo de identificação do objeto referido pelo termo singular é independente do modo de identificação de tropos contingentes que dele se predicam, enquanto o sentido da expressão predicativa, o modo de identificação desses tropos, é dependente da prévia identificação do objeto referido pelo termo singular.

Devemos também notar que a relação de independência/dependência não precisa restringir-se a particulares empiricamente dados. Até mesmo os objetos formais prioritariamente considerados por Frege parecem submeterse a ela. Considere uma predicação como '...é um número par' aplicada à referência do nome próprio ' 6 '. Ela depende do reconhecimento da existência do número 6 . E o próprio conceito de ser um número par não parece ter lugar na independência da existência dos número particulares 2, $4,6 \ldots$ que são pares.

Essa espécie de solução parece finalmente viável pelo fato de ela em princípio explicar a assimetria entre objeto particular e propriedade. Ela se explica da independência da referência do termo singular. $O$ nome 'Sócrates' não pode passar à posição de predicado porque aquilo a que ele se refere é algo independente (e independentemente identificável), ou seja, é o sistema de tropos que constitui essencialmente o objeto particular. Mesmo 
o nome de um objeto abstrato como o número ' 6 ' não pode passar à posição de predicado, posto que se refere a algo relativamente independente de suas propriedades (alegadamente não as que lhe são definitórias), ou ao menos identificável independentemente de muitas de suas predicações, digamos '...é par' ou '...é maior do que 2 '.

\section{Sentido do termo geral}

Frege não explica o que ele entende pelo sentido do termo geral em sua função predicativa. Isso é compreensivel, já que ele não pode mais chamá-lo de conceito. Mas a lógica de nossa interpretação nos leva a pensar que esse sentido, o modo de apresentação, nada mais seja do que o que poderíamos chamar de a regra de caracterização (ou de aplicação) do termo geral e que essa regra seja aquilo que merece ser chamado de conceito. $^{15}$

Tal como acontece com o sentido do termo singular, o sentido do termo geral também pode se alterar sem que a sua referência se altere. Considere as frases:

\section{A Lua é branca.}

2. A Lua reflete todos os comprimentos de onda.

A referência, os conjuntos de arranjos de tropos que constituem a brancura da Lua, permanece a mesma nas frases (1) e (2), mas os sentidos dos predicados são diversos, o que faz com que os sentidos das frases sejam diferentes: uma pessoa pode saber que a Lua é branca sem saber que a sua superfície reflete todos os comprimentos de onda do aspectro visível.

A distinção entre independência/dependência (saturação/insaturação) também se reflete para Frege ao nível do sentido. Isso fica compreensível se pensarmos o sentido do termo geral como regra. A regra de identificação do termo singular se aplica ao objeto, o qual é considerado como independente em relação às propriedades singularizadas que lhes são contingentemente predicadas. Por isso a regra de identificação também é passível de ser

15 Ernst Tugendhat usou a expressão Verwendungsregel (regra de aplicação) para nomear a regra de designação do predicado. Ver E. Tugendhat: Logisch-Semantische Propaedeutik (Reclam: Stuttgart 1983), cap. 13. 
aplicadas independentemente das regras de caracterização, podendo ser ela mesma isoladamente concebível em sua aplicação, sendo nesse sentido independente, completa, saturada. O mesmo não acontece, porém, com as regras de caracterização expressas pelos termos gerais. Sendo os tropos ou conjuntos de tropos aos quais elas ultimamente se aplicam dependentes dos sistemas de tropos constitutivos dos objetos aos quais as regras de identificação se aplicam, as regras de caracterização dos predicados demandam a aplicação prévia das regras de identificação de objetos para poderem se tornar elas próprias aplicáveis, o que as torna dependentes das regras de identificação dos termos singulares, do mesmo modo que as propriedades são dependentes dos objetos que as possuem. ${ }^{16} \mathrm{O}$ sentido do termo geral, que (divergindo de Frege) podemos identificar com o conceito por ele expresso, deve ser então uma regra cuja aplicação a um objeto depende da prévia aplicação de outra regra. A regra de caracterização do termo predicativo é dependente e por isso ela mesma incompleta, insaturada, pois ela demanda a aplicação prévia da regra identificadora do termo singular para poder se aplicar. É preciso em suficiente medida identificar, ou seja, localizar no espaço e no tempo algum objeto particular, para então poder caracterizar. É preciso aplicar a regra que nos permite, por exemplo, localizar espaço-temporalmente o animal chamado Bucéfalo para, com base nisso, aplicar-lhe regras de caracterização de termos gerais como '...é um cavalo', ‘...é branco', ‘...é dócil'. E é preciso aplicar a regra que nos permite identificar mentalmente o número 6 para podermos dizer que ele é um número par.

Seria uma objeção ingênua a de que afinal de contas é possível dizer “Aquilo é um cavalo" ou "Lá está uma coisa branca", sem identificar Bucéfalo, pois isso não chega a ser necessário. Termos singulares indexicais como 'aquilo' e 'lá' já identificam algum particular na forma de alguma coisa espaço-temporalmente localizável de modo independente, explicitável por expressões como 'aquele animal', 'aquele objeto', 'aquele lugar', e isso

\footnotetext{
${ }^{16}$ Essa dependência que a aplicação da regra predicativa tem de uma prévia aplicação da regra de identificação do termo singular foi notada, por exemplo, por Ernst Tugendhat em sua análise das condições de verdade da frase predicativa singular: "Fa' é exatamente então verdadeira se, na medida em que a regra de identificação de 'a' foi seguida, com base no resultado do seguimento dessa regra, ' $F$ ' for aplicável de acordo com a sua regra de aplicação". E. Tugendhat: Logisch-Semantische Propedeutik, ibid. p. 235.
} 
basta. Por isso, não só a referência do predicado é dependente, mas também o seu sentido. A relação de dependência semântica - ao nível do sentido espelha a relação de dependência ontológica - ao nível da referência.

\section{0 conceito de existência}

Nesse ponto podemos adicionar uma consideração especial sobre o conceito de existência. Aprofundando um insight kantiano, Frege sugeriu que a existência é uma propriedade (Eigenschaft) do conceito, qual seja, a propriedade que este tem de não ser vazio, mas satisfeito, preenchido. ${ }^{17}$ Considerando que um conceito de primeira ordem preenchido é aquele sob o qual cai ao menos um objeto, podemos dizer que para Frege a existência é a propriedade de um conceito de sob ele cair pelo menos um objeto. A mesma idéia foi defendida por Russell na sugestão de que a existência é a propriedade de uma função proposicional do tipo "Ex(...)" de ser verdadeira para ao menos uma instância. ${ }^{18}$

Seguindo uma terminologia mais atual, tomemos como exemplo a frase geral "Cavalos existem". ${ }^{19}$ Essa frase se deixa analisar como:

Existe ao menos um $x$ tal que $x$ é um cavalo.

Essa frase contém dois componentes. Um deles é expresso pelo predicado '...é um cavalo', simbolicamente $\mathrm{C} x$ (onde $x$ está no lugar de '...'

\footnotetext{
17 Ver Gottlob Frege: Die Grundlagen der Arithmetik (Felix Meiner Verlag: Hamburg 1986), sec. 53.

${ }_{18}$ Bertrand Russell: "The Philosophy of Logical Atomism", pp. 232, 250-54. Essa posição sustentada por Russell e Frege é disputada por muitos filósofos contemporâneos, que preferem considerar a existência como uma predicação de primeira ordem. As razões aduzidas me parecem contornáveis. João Branquinho, por exemplo, sugere que só podemos analisar uma frase como "Há coisas que não existem" se admitirmos que predicados de existência são de primeira ordem, enquanto quantificadores significam apenas uma atribuição de "ser" no sentido meinonguiano. Assim, a simbolização da frase acima seria $\sum x\left(\sim\right.$ Ex), onde $\sum$ significa 'há' (ver "Existência", in Enciclopédia de Termos Lógico-Filosóficos, eds. J. Branquinho, D. Murcho e N.G. Gomes, Martins Fontes: São Paulo 2006, p. 300). Mas a frase acima também poderia ser analisada ao modo fregeano. Podemos traduzi-la como "Existem coisas na mente que não existem na realidade externa". Nesse caso, sendo $M=$ "...na mente" e $R=$ "...na realidade externa", parece que podemos simbolizar "Há coisas que não existem" como $\operatorname{Ex}((\mathrm{Mx}) \& \sim \operatorname{Ex}(\mathrm{Rx}))$. Essa discussão, porém, foge aos limites do presente texto.

19 Ver J.R. Searle: "The Unity of Proposition", in Philosophy in a New Century (Cambridge University Press: Cambridge 2008), p. 176.
} 
e C no lugar de 'é um cavalo'). O outro componente é o predicado de existência, a frase aberta 'Existe ao menos um...tal que...', simbolicamente $\mathrm{Ex}(. .$.$) (onde E está no lugar de 'Existe ao menos um, e '...' é a lacuna a ser$ preenchida por algum conceito'. Isso significa que a predicação de existência $\operatorname{Ex}(. .$.$) é um conceito de conceito, um conceito de ordem$ superior, um metaconceito sob o qual pode cair algum outro conceito. A frase $\mathrm{E} x(\mathrm{Cx})$ expressa, pois, um conceito de segunda ordem aplicado a um conceito de primeira ordem. O que esse conceito de ordem superior faz é, no dizer de Frege, dizer que ao menos um objeto cai sob o conceito de primeira ordem, ou seja, atribuir a satisfação ou a aplicação desse conceito de primeira ordem a ao menos um objeto. Quando dizemos que cavalos existem estamos usando um conceito de segunda ordem, de aplicabilidade a ao menos um objeto, o qual é aplicado a um conceito de primeira ordem.

Essa mesma idéia pode ser estendida a afirmações de existência de portadores de nomes próprios através da transformação dos últimos em predicados, como acontece quando formalizamos "Sócrates existe" como "Ex( $x=$ Sócrates)", o que é inadequado por razões formais, ou " $E x(x$ socratiza)" ${ }^{\prime 20}$, o que é lingüisticamente estranho. A estranheza dessa última fórmula pode ser desfeita se entendermos o verbo socratizar como uma abreviação de descrições definidas, de modo que "Ex(x socratiza)" fique sendo, para ilustrar, algo como

Ex( $x$ foi o inventor da maiêutica, $x$ foi o mestre de Platão, $x$ foi o marido de Xantipa etc.).

Uma vez feito isso podemos analisar as descrições definidas russellianamente, valendo-nos apenas de predicados quantificados como:

\footnotetext{
${ }^{20}$ Se entendermos (i) "Ex(x = Sócrates)" como exprimindo uma relação de identidade entre $x$ e Sócrates, estaremos diante de um problema insolúvel, pois não teremos mais como negar a existência. Considere, por exemplo, (ii) " $\operatorname{Ex} \operatorname{Ex}(x=$ Sócrates)". Segundo o princípio da generalização existencial, os nomes podem ser nesse caso substituídos por variáveis. Nesse caso (ii) pode ser substituido por (iii): " $\operatorname{Ey}$ Ex(x = y)". Mas isso é o mesmo que dizer que algo que não existe, existe. Por isso, ao invés de (i) preferimos adotar (iv) "Ex(x socratiza)", pois (iv) pode ser negado por (v) " $\operatorname{Ex} \operatorname{Ex}(x$ socratiza)", sobre o que não podemos aplicar o princípio da generalização existencial.
} 
Ex $x$ foi inventor da maiêutica e exatamente um $x$ foi inventor da maiêutica, $x$ foi mestre de Platão e exatamente um $x$ foi mestre de Platão, $x$ foi marido de Xantipa e exatamente um $x$ foi marido de Xantipa etc.)

É verdade que essa explicação descritivista dos nomes próprios encontra dificuldades nas objeções feitas por Kripke, Donnellan e outros à teoria do agregado dos nomes próprios que ela pressupõe. Mas é preciso notar que, diversamente de um preconceito corrente, essas objeções pouco afetam versões mais sofisticadas da teoria descritivista, tendo sido respondidas em sua maioria por J.R. Searle. ${ }^{21}$ Além disso, a versão mais elaborada da teoria do agregado, por mim mesmo proposta (que organiza o feixe por meio de metadescrições e não deixa de incorporar elementos causais-históricos) possui (em meu modesto juizo) maior poder explicativo do que qualquer teoria anterior e responde mais completamente aos contraexemplos conhecidos. ${ }^{22}$

A grande vantagem da maneira de conceber a existência propugnada por Frege é que não encontramos problemas em negá-la. Se ao dizer "Vulcano não existe" a negação da existência devesse ser aplicada ao próprio objeto, teríamos primeiro de identificar o objeto, para então podermos negar que ele possui a propriedade de existir. Mas como para identificar o objeto precisamos admitir que ele existe, nós caímos em contradição. Ou seja: teríamos de admitir que a existência de Vulcano não pode ser negada. Mas pela concepção de Frege-Russell isso não é necessário. Pois tudo o que fazemos ao negar a existência de Vulcano é admitir que o conceito de Vulcano não cai no conceito de existência por não ser um conceito preenchido ou satisfeito ou efetivamente aplicável. Substituindo o nome 'Vulcano' pelo predicado 'vulcaniza', a sentença fica sendo " $\mathrm{E} x$ ( $x$ vulcaniza)", ou, na análise proposta “ $\mathrm{E} x(x$ é o planeta que orbita entre Mercúrio e o Sol)" ou, mais detalhadamente, “ $\sim \mathrm{E} x$ ( $x$ é um planeta que orbita entre Mercúrio e o Sol e para qualquer $y$, se $y$ for um planeta que orbita entre Mercúrio e o Sol, $y=x$ )..."

21 Ver J.R. Searle: Intentionality (Cambridge University Press: Cambridge 1983), cap.9.

Ver também as avaliações de David Braun e Marga Reimer em seus respectivos artigos para a Stanford Encyclopedia of Philosophy (internet).

22 C.F. Costa: "A Meta-Descriptivist Theory of Proper Names", Ratio 24, 2011. 
Em suma; admitindo - em desacordo com a terminologia artificial de Frege - que aquilo que chamamos de conceitos são os sentidos dos termos predicativos, e não as suas referências, e aceitando a venerável idéia kantiana de que conceitos são regras, podemos parafrasear a noção fregeana de existência como sendo a do preenchimento ou satisfação da regra conceitual, ou seja, da regra de caracterização do termo predicativo. Além disso, considerando que o preenchimento ou satisfação de um conceito ou regra conceitual nada mais é do que a sua aplicação à propriedade correspondente (supostamente tropos ou complexos de tropos) de ao menos um objeto particular, podemos também dizer que a atribuição de existência nada mais é do que a atribuição de aplicabilidade de uma regra conceitual a ao menos um objeto. Essa aplicabilidade da regra conceitual é que produz a verdade da frase aberta do tipo $\operatorname{Ex}(. .$.$) , ou seja, a verdade da atribuição de$ existência pela satisfação do conceito por algo que sob ele cai.

\section{A referência das frase}

Passemos agora à referência da frase (Satz) em Frege. Ele a entende como devendo ser aquilo que permanece o mesmo quando mudamos o sentido dos componentes da frase sem alterar a sua referência. Isso acontece quando substituímos "A estrela da manhã é iluminada pelo sol” por "A estrela da tarde é iluminada pelo sol”; aqui as referências dos componentes permanecem as mesmas. Logo, a referência da frase também deve permanecer a mesma. Mas o que não se alterou? A resposta de Frege é: o valor-verdade. Ambas as frases permanecem verdadeiras. Disso ele conclui que ao menos na linguagem extensional a referência das frases é o seu valor-verdade. Em adição a isso Frege nota que a busca da verdade é o que nos leva do sentido para a referência. E o valor-verdade é certamente da maior importância (Bedeutung) para a lógica, por ser aquilo que deve ser preservado em argumentos válidos.

Não obstante, independentemente de qualquer vantagem teórica que essa sugestão possa trazer, ela é profundamente implausível. A conseqüência anti-intuitiva óbvia de se supor que a referência da frase seja o seu valor-verdade é que todas as frases verdadeiras passam a ter a mesma referência, que é o Verdadeiro (das Wahre), enquanto todas as frases falsas passam a ter como referência o Falso (das Falsche). Contudo, é completamente contra-intuitivo que frases que nada têm em comum, como 
" $2+2=4$ " e "Napoleão nasceu na Córsega" tenham a mesma referência; tão contra-intuitivo quanto a sugestão de que uma frase como " $2+2=4$ é o mesmo que Napoleão nasceu na Córsega", por conter duas frases referindose ao Verdadeiro, seja verdadeira. Além disso, a referência da frase, que deveria pertencer ao mesmo domínio ontológico da referência dos seus componentes, passa usualmente para outro domínio: enquanto a referência do nome 'Napoleão' é o próprio Napoleão de carne e osso, a referência de "Napoleão nasceu na Córsega" é o objeto abstrato oVerdadeiro. Por fim, mesmo sob a perspectiva da semântica fregeana essa idéia é falsa, pois viola o princípio da composicionalidade: a referência da frase, sendo o seu valorverdade, não pode ser constituída da referência de suas partes.

Esse resultado é tanto menos aceitável por existir uma alternativa muito mais intuitiva à mão, a qual não é sequer aventada por Frege. ${ }^{23}$ Podemos, como Wittgenstein, Russell e outros fizeram, admitir que a referência de uma frase possa ser o fato verificador último, que podemos chamar de seu fato fundamentador, que tanto pode ser estático (situação, estado de coisas...) como dinâmico (evento, processo, acontecimento...). Essa alternativa envolve dificuldades e carece de desenvolvimento adequado. A questão básica é a de estabelecer o que é o fato fundamentador. Se raciocinarmos ao modo de Frege, esse fato precisa ser algo que não se modifica quando alteramos o sentido de componentes da frase sem alterarmos as referências desses componentes. Isso quer dizer que as frases

Exemplo I:

1. A estrela da manhã é a estrela da manhã,

2. A estrela da manhã é a estrela da tarde,

3. A estrela da manhã é Vênus,

4. Vênus é o segundo planeta a orbitar o sol,

5. A estrela da manhã é o segundo planeta a orbitar o sol.

precisam designar um mesmo fato. A questão é: existe uma descrição privilegiada do fato fundamentador que ultimadamente verifica os

${ }^{23}$ Anthony Kenny: Frege: An Introduction to the Founder of Analytic Philosophy (Oxford: Blackwell 1995), p. 133. 
pensamentos expressos por todas essas frases, além dos pensamentos expressos por um número indeterminado de outras frases de identidade que podem ser produzidas acerca de Vênus? Minha sugestão é a de que essa tarefa pode ser realizada por frases de identidade entre nomes próprios. Admitindo por hipótese que em sua intuição fundamental a teoria dos nomes próprios como abreviações de agregados de descrições, aparentemente sugerida por Frege seja correta, então o nome próprio 'Vênus' abrevia em seu sentido modos de apresentações exprimíveis através de descrições como 'a estrela da manhã', 'a estrela da tarde', 'o segundo planeta a orbitar o sol' etc. Ora, nesse caso a frase "Vênus é (o mesmo que) Vênus" seria capaz de descrever o fato fundamentador das verificações das frases de 1 a 4 e outras mais. Por exemplo: se o nome 'Vênus' abrevia as descrições 'a estrela da manhã' e 'a estrela da tarde', de "Vênus é Vênus" podemos derivar a frase 2 e na verdade todas as outras.

\section{Sentido da frase: 0 pensamento}

Passemos agora ao sentido da frase. Aqui Frege fez uma constatação definitiva, qual seja, a de que o sentido da frase completa é o pensamento (Gedanke) por ela expresso. Ele chega a esse resultado pela aplicação do seu princípio da composicionalidade, segundo o qual o sentido de uma expressão complexa é formado pelos sentidos de suas expressões componentes apresentadas em certa ordem. Se, por exemplo, na frase "A estrela da manhã é um planeta" substituirmos a expressão 'a estrela da manhã' por 'a estrela da tarde', que é co-referencial, mas de sentido diverso, a referência da frase não pode mudar, mas muda o sentido, e muda, sem dúvida, o pensamento por ela veiculado. Como o pensamento é aquilo que se modifica quando uma expressão componente da frase é substituída por uma expressão co-referencial com sentido diverso, Frege concluiu muito coerentemente que o pensamento é o sentido da frase.

A palavra 'pensamento' é ambígua. Ela também pode ser usada para designar um processo psicológico de pensar, como na frase "Estava agora mesmo pensando em você!". Mas ela também parece designar algo que independe de ocorrências mentais particulares, um conteúdo de pensamento como o expresso pelo proferimento "O pensamento expresso pela frase $12 \mathrm{x}$ $12=144$ é verdadeiro". Frege tinha esse último sentido em mente. Nesse sentido a palavra 'pensamento' é o único correspondente na linguagem 
natural a termos técnicos denotadores daquilo que a frase diz, como 'proposição', 'conteúdo proposicional' ou 'conteúdo enunciativo' ${ }^{24}$

Para Frege faz parte do pensamento tudo o que contribui para a determinação do valor-verdade da frase. Por isso as frases "A estrela da manhã é Vênus" e "A estrela da tarde é Vênus" podem ser contadas como exprimindo pensamentos diferentes: os termos singulares que compõem essas duas frases de identidade referem-se ao mesmo planeta, mas por modos de apresentação diferentes, por diferentes caminhos determinadores do seu valor-verdade, ou ainda, por diferentes regras de identificação constitutivas dos seus procedimentos verificacionais. (Já as sentenças "Alfredo não chegou" e "Alfredo ainda não chegou" expressam o mesmo pensamento, pois segundo Frege o advérbio 'ainda' exprime apenas uma expectativa sobre a chegada de Alfredo, não contribuindo para o valorverdade..$^{25}$ )

\section{0 pensamento como o portador da verdade}

Outra sugestão fregeana bastante plausível é a de que o portador da verdade não é a frase, mas o pensamento. Para Frege aquilo que dizemos ser verdadeiro (ou falso) deve ser sempre verdadeiro (ou falso) e só o pensamento, sendo imutável, possui a estabilidade requerida. Eis o argumento: Frases idênticas exprimindo pensamentos diferentes podem possuir diferentes valores-verdade; esse é o caso da frase indexical "Sinto dores", cujo pensamento se altera com o falante. E frases diferentes exprimindo o mesmo pensamento, como "It rains" e "Il pleut", proferidas no mesmo contexto, devem ter o mesmo valor-verdade. Assim, na relação entre pensamento e valor-verdade há uma co-variância que falta à relação entre frases e valor-verdade, o que nos leva à conclusão de que o portador da verdade é o pensamento e não a frase. ${ }^{26}$

\footnotetext{
${ }^{24}$ Como nota Tyler Burge em "Sinning against Frege", "a palavra 'pensamento' é o melhor substituto de 'proposição' por sua naturalidade semântica dentro do escopo apropriado à filosofia linguística", in T. Burge: Truths, Thoughts, Reason: Essays on Frege (Clarendon Press: Oxford 2005), pp. 227-8.

25 G. Frege: "Der Gedanke", Beitrage zur philosophie des deutschen Idealismus I, 2, 1918, p. 64 (paginação original).

${ }_{26}$ C.F. Costa: "O verdadeiro portador da verdade", in Cartografias conceituais: uma abordagem da filosofia contemporânea (Edurfn: Natal 2008).
} 
Frege também sugeriu que aquilo que chamamos de fato é o pensamento verdadeiro, pois quando o cientista descobre um pensamento verdadeiro ele diz que descobriu um fato. ${ }^{27}$ Mas essa conclusão não é forçosa, pois o cientista também poderá dizer a mesma coisa - e com mais propriedade - entendendo por fato aquilo que corresponde ao seu pensamento verdadeiro, afinal, é intuitivo pensar que se ele descobre o pensamento verdadeiro é porque a fortiori ele descobriu o fato que lhe é correspondente. A razão pela qual Frege pensava que o fato é o pensamento verdadeiro é, aliás, que ele defendia uma concepção da verdade como redundância. A mais natural e plausível concepção de verdade, porém, é a correspondencial, a qual nos sugere que fatos são complexos de elementos no mundo em algum nível isomórficos aos pensamentos que visam representá-los. ${ }^{28}$ No que se segue irei adotar a concepção correspondencial da verdade em minha revisão dos sentidos fregeanos em termos de regras semântico-cognitivas para ver até onde isso nos levará.

\section{0 pensamento como a própria regra de verificação}

Também os pensamentos podem ser parafraseados em termos de regras semânticas. Para tal precisamos admitir, mesmo que especulativamente, que uma máxima proposta pela primeira vez por Wittgenstein aos membros do Círculo de Viena, o muito criticado princípio da verificação, segundo o qual o sentido cognitivo da frase é a sua regra (método, procedimento) de verificação, seja correto. ${ }^{29}$ Se supusermos que o sentido cognitivo da frase seja a sua regra de verificação e admitindo que o sentido da frase é o pensamento por ela expresso, então esse pensamento nada mais é do que a própria regra de verificação da frase. Como o sentido da frase deve ser uma combinação de regras semânticas, o mesmo se pode dizer do pensamento, da regra de verificação, que no caso da frase predicativa singular nada mais deve ser do que uma combinação da regra

\footnotetext{
${ }^{27}$ Gottlob Frege: "Der Gedanke", a.a.O. p. 74.

${ }^{28}$ C.F. Costa: "A verdadeira teoria da verdade", in Cartografias conceituais: uma abordagem da filosofia contemporânea, (Edufrn: Natal 2008).

${ }^{29}$ Em meu juízo, ao menos da maneira flexível proposta por Wittgenstein, esse princípio nada tem de implausível. Mas não tenho aqui espaço para argumentar a favor desse ponto de vista.
} 
de identificação do objeto (sentido do termo singular) com a regra de caracterização do predicado (sentido do termo predicativo).

A identificação que em termos especulativos estou propondo entre sentido-pensamento e regra de verificação da frase é reforçada pela sugestão fregeana de que o critério para identificarmos aquilo que pertence ao pensamento é ter algum papel no estabelecimento de sua verdade. Sendo assim, então o sentido-pensamento da frase é o mesmo que o significado cognitivo identificado pelo verificacionista com a regra (procedimento, método) que permite o reconhecimento da verdade da frase, o que costuma redundar para Wittgenstein em um ramificado de procedimentos verificacionais possíveis. ${ }^{30}$ Ora, se o pensamento é o portador da verdade e ele é a regra de verificação, então é a própria regra de verificação que é o portador da verdade (não em casos concretos de sua aplicação, obviamente, mas na abstração deles). E como o que torna o pensamento verdadeiro (assumindo a teoria correspondencial) é a sua correspondência com o fato, o que torna a regra de verificação verdadeira deve ser a correspondência das configurações criteriais por ela demandadas com aquilo que às satisfaz e, em última análise, com o fato (ou os fatos) no mundo. Mas isso é o mesmo que dizer que a regra de verificação é verdadeira quando ela é satisfeita ou preenchida, melhor dizendo, quando ela é efetivamente aplicável. Assim, o pensamento será considerado verdadeiro quando a regra de verificação que o constitui se demonstrar aplicável; e ele será considerado falso quando a regra de verificação que o constitui não se demonstrar aplicável. Daí que a efetiva e contínua aplicabilidade da regra de verificação é o mesmo que a verdade do pensamento, enquanto a sua efetiva e contínua inaplicabilidade é o mesmo que a sua falsidade. E o fato,

\footnotetext{
30 Como notou Wittgenstein em uma passagem que mostra a peculiaridade de sua abordagem do sentido como regra de verificação: "A consideração do modo como o significado de uma sentença é explicado torna clara a conexão entre significado e verificação. Ler que Cambridge ganhou a corrida de botes, o que verifica "Cambridge venceu", obviamente não é o significado, mas é conectado com ele. "Cambridge venceu" não é a disjunção 'eu vi a corrida ou eu li o resultado ou...' É mais complicado. Mas se excluirmos qualquer um dos meios de verificar 0 enunciado, nós alteraremos o seu significado. Seria uma infração de nossa gramática se nós excluíssemos da verificação algo que sempre acompanhou 0 significado. E se excluíssemos todos os meios de verificação, isso iria destruir o significado. É claro que nem toda espécie de verificação é realmente usada para verificar "Cambridge venceu" nem qualquer verificação dará o significado. As diferentes verificações do vencer a corrida de barcos têm diferentes lugares na gramática de "ter vencido a corrida de botes". L. Wittgenstein: Wittgenstein's Lectures, Cambridge 1932-1935 (Oxford University Press: Oxford 1986), p. 29.
} 
sob esse entendimento, não deixa de ser uma combinação de elementos dados no mundo. Por sua vez, essa combinação deve satisfazer a regra verificacional quando ele é correspondente, por isomorfismo estrutural, às combinação de configurações criteriais demandadas pela regra verificacional para que ela possa se demonstrar efetivamente aplicável. O que chamamos de juízo, por sua vez, é o reconhecimento que o sujeito epistêmico faz da efetiva aplicabilidade da regra verificacional, de que a verificação de algum modo foi realizada. Por isso dizer "É verdade que $p$ ", "Eu ajuízo que $p$ " ou "Eu afirmo que $p$ " são coisas similares.

Essas admissões conjecturais sugerem uma inesperada proximidade entre os conceitos de verdade e existência. Pois o conceito de verdade aplicado ao conteúdo de pensamento se demonstra análogo ao conceito de existência aplicado ao conteúdo conceitual. Considere: a verdade é a efetiva aplicabilidade da regra verificacional constitutiva de um conteúdo de pensamento, enquanto a existência é a efetiva aplicabilidade da regra de caracterização ou identificação constitutiva de um conteúdo conceitual. Em outras palavras: assim como a existência é a propriedade de segunda ordem do conceito de sob ele cair um objeto, a verdade deve ser a propriedade de segunda ordem do pensamento de sob ele "cair" o fato que lhe corresponde. Ela é, pois, o correspondente da existência ao nível da combinação de sentidos que constitui o pensamento. Ou ainda, expressando-nos de um modo um tanto hegeliano: a verdade é a existência do pensamento, enquanto a existência é a verdade do conceito.

Email: oidualc@digi.com.br

Recebido em: Abril de 2011

Aprovado em: Maio de 2011 